\title{
An Unusual Finding of Double Fused Y- Shaped Loop of Ansa Cervicalis and its Clinical Significance
}

\author{
SHILPI AGARWAL, POOJA BHADORIA, NEELAM VASUDEVA
}

\section{ABSTRACT}

The ansa cervicalis $(A C)$ is a neural loop formed by union of superior root derived from ventral ramus of $\mathrm{C} 1$ through hypoglossal nerve and inferior root derived from ventral rami of $\mathrm{C} 2$ and $\mathrm{C} 3$. The aim of this case report is to emphasize the anatomical description and surgical importance of a rare variation of $\mathrm{AC}$ owing to its closeness with major vessels and nerves of neck. An unusual double fused Y-shaped loop pattern of ansa cervicalis was observed on the right side of the neck of a 50 years old male cadaver in which the inferior root had separate C2 and C3 components. The C2 component joined the superior root of $\mathrm{AC}$ to form the Y-shaped superior loop. The stem of the superior loop joined the ventral rami of C3 root to form the inferior loop. Knowledge of variations in origin, course and pattern of distribution of ansa cervicalis is important since the branches of ansa cervicalis are often chosen for laryngeal reinnervation of the laryngeal muscles following recurrent laryngeal nerve palsy and also to avoid iatrogenic injuries during surgical procedures of the neck.

\section{CASE REPORT}

During routine dissecton as a part of undergraduate teaching schedule, we observed a double loop pattern of ansa cervicalis (AC) on the right side of the neck of a 50 years old male formalin fixed cadaver. On the left side, no such variation was found in the ansa cervicalis formation.

On the right side of the neck, $\mathrm{AC}$ presented a double fused $\mathrm{Y}$ shaped loop pattern lying lateral to the internal jugular vein. The superior root $(\mathrm{C} 1)$ or descendens hypoglossi of $A C$ originated from hypoglossal nerve as usual. The inferior root of AC or descendens cervicalis, instead of joining the superior root as a single nerve, had separate C2 and C3 components which contributed in formation of two loops of $\mathrm{AC}$. The ventral rami of $\mathrm{C} 2$ joined with the superior root of $\mathrm{AC}$ and formed a smaller superior loop on the lateral aspect of Internal jugular vein. A branch to superior belly of omohyoid arised from descendens hypoglossi of superior loop. The stem of the upper Y-shaped superior loop traversed inferiorly to join with the ventral rami of C3 root and formed the larger inferior loop. Branch to inferior belly of omohyoid arose from descendens cervicalis (C3) of the inferior loop. Branches to sternothyroid and sternohyoid muscles arose from the stem of the inferior Y-shaped loop [Table/Fig 1,2].

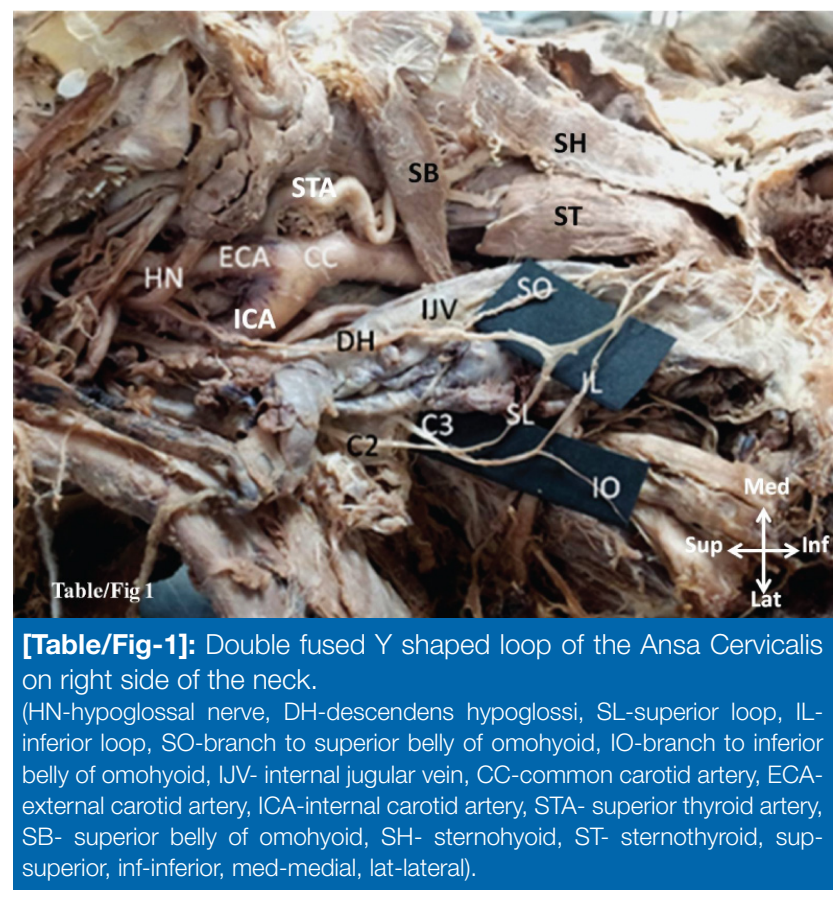

\section{DISCUSSION}

Variations in course, location and arrangement of the contributing roots and branching pattern of $\mathrm{AC}$ pose a great 


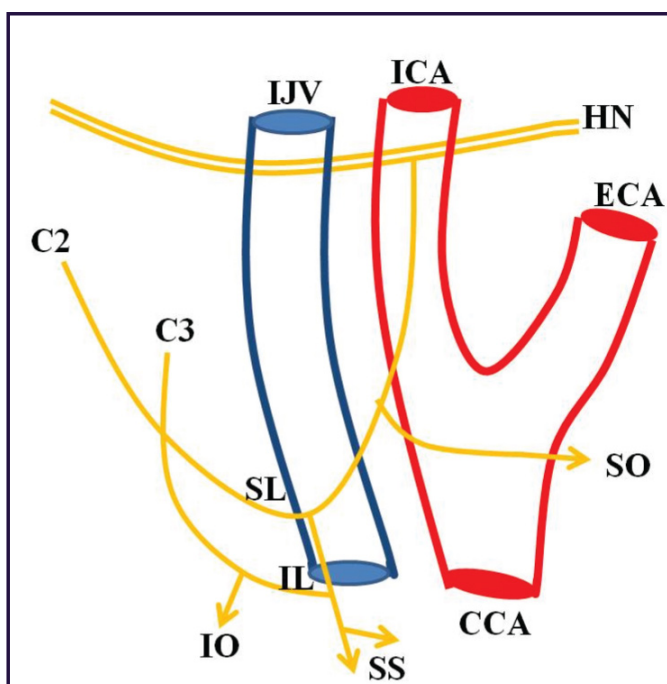

[Table/Fig-2]: Schematic line diagram showing double fused $Y$ shaped loop pattern of the Ansa Cervicalis.

(HN-hypoglossal nerve, IJV-internal jugular vein,CCA-common carotid artery, ECA-external carotid artery, ICA-internal carotid artery, SL-superior loop, ILinferior loop, SO-branch to superior belly of omohyoid, 1O-branch to inferior belly of omohyoid, SS-branch to sternohyoid \& sternothyroid)

challenge to surgeons during various surgical procedures of the neck such as in thyroplasty, arytenoids adduction, Teflon injection, nerve-muscle pedicle implantation, skull base surgery and neck dissection [1]. latrogenic injury to AC during such procedures can lead to change in voice quality as the infrahyoid muscles supplied by AC have role in laryngeal steadiness and excursion during phonation [2].

Ahmed (2013) reported that among the four patterns of AC formation observed by him, Type 1 ( $U$ shaped loop) was the commonest (84\%) followed by Type 2 ( $Y$ shaped loop) in $8 \%$, Type 3 (double fused $Y$ shaped loop) in 4\% and Type 4 (double separate $Y$ shaped loop) in 4\% [3]. Double fused $Y$ shaped loop seen in the present case is similar to the Type 3 and is rarely observed. Loukas et al., has observed variability in the origin of inferior root of $\mathrm{AC}$ and reported its origin from C2, C3 in 38\%, from C2, C3, C4 in 10\%, from C3 only in $40 \%$ and from $\mathrm{C} 2$ only in $12 \%$ of cases. He also found that the inferior root was posterolateral to Internal Jugular vein in $74 \%$ and anteromedial to it in $26 \%$ of cases [1]. In the present case, the inferior root had separate nerve components of C2 and C3 and it was posterolateral to Internal Jugular vein.

Our finding that $\mathrm{AC}$ was present superficial and lateral to internal jugular vein, i.e. lateral type, is in accordance to Banneheka and Mwachaka et al., who found this in 75\% and $81.5 \%$ of cases repectively $[4,5]$.

The observation in the present case that superior root of $A C$ gave origin to superior belly of omohyoid is in agreement with Liguoro et al., [6]. Branch to inferior belly of omohyoid arose from inferior root in the current case which was also reported by Banneheka [4].
Ravindra et al., and Kumar $\mathrm{N}$ et al., have also reported double fused $Y$ loop but in later the loops were located deep to internal jugular vein and in both the infrahyoid muscles were supplied by inferior loop $[7,8]$. Rao et al., reported a double loop pattern in which superior loop was formed by descendens hypoglossi and descendens vagi and a branch from superior loop joined with descendens cervicalis to form inferior loop [9]. AC formation and branching pattern found in the current case is multivariable and unique which has been reported very rarely previously.

Recurrent laryngeal nerve may be damaged in patients of thyroid cancer due to local invasion, in oesophageal cancer patients following lymphadenectomy and during carotid endarterectomy. AC has been increasingly used for laryngeal reinnervation due to its proximity to the larynx. Use of AC for nerve to nerve anastomosis to the recurrent laryngeal nerve has not reported any serious functional or cosmetic consequences [10]. Branch of AC to the sternothyroid has given good results with vocal quality due to the fact that it is located very near to the recurrent laryngeal nerve [11]. Recently, nerve- muscle transplantation to the paraglottic space with $\mathrm{AC}$ has become the method of choice for laryngeal reinnervation [1].

The AC nerve has also been used to prevent the morbidity associated with the tongue hemiatrophy after facialhypoglossal anastomosis [12]. Knowledge of the variation in nerve supply to infrahyoid muscles is helpful for the surgeons during harvesting the muscle flap for renovating vocal fold or for laryngotracheal reconstruction [13].

The developing axons of the spinal nerve, which innervate the myoblasts for the infrahyoid muscles, are regulated by expression of chemoattractants and chemorepellents in highly coordinated site specific fashion. Any alterations in such signaling may lead to significant variations which would persist postnatally [14]. This explains the probable reason for the variant morphology found in the present case.

\section{CONCLUSION}

Knowledge of the variable topography and morphology of $\mathrm{AC}$ is of immense importance for laryngeal innervations surgeries, for procedures requiring infrahyoid muscle flaps and to prevent inadvertent injuries of the nerve loop. The surgeons should be conversant with such variations to enhance the success of the surgeries with minimal untoward effects.

\section{REFERENCES}

[1] Loukas M, Thorsell A, Tubbs RS, Kapos T, Louis RG Jr, Vulis M, Hage R, Jordan R. The ansa cervicalis revisited. Folia Morphol (Warsz). 2007; 66: 120-25.

[2] Navak SR, Rai R, Krishnamurthy A, PrabbuLV, Potu BK. An anomalous belly of sternothryoid muscle and its significance. Rom J Morphol Embryol. 2009; 50 (2): 307-08.

[3] Ahmed MS. Anatomical study of the human ansa cervicalis nerve and its variations. Int J Anat Physiol. 2013; 2(3):14-19. 
[4] Banneheka S. Morphological study of the ansa cervicalis and the phrenic nerve. Anat Sci Int. 2008; 83(1):31-44.

[5] Mwachaka PM, Ranketi SS, Elbusaidy H, Ogeng'o J. Variations in the anatomy of ansa cervicalis. Folia Morphol (Warsz). 2010; 69(3):160-63.

[6] Liguoro D, Vital JM, Guerin J. Anatomical basis of the anterior cervical spine approach: Topographic study of the nerve structure. Surg Radiol Anat. 1992; 14: 203-08.

[7] Ravindra SS, Kumar N, Nayak SB, Mohandas Rao KG, Jyothsna $P$, Anitha G. Unusual looping pattern of ansa cervicalis: Case report. OA Case Reports. 2013; 2(9):81.

[8] Kumar N, Patil J, Mohandas RKG, Sirasanagandla SR, Nayak SB, Guru A. Rare case of double looped ansa cervicalis associated with its deep position in the carotid triangle of the neck. Ann Med Health Sci Res. 2014; 4: 29-31.

[9] Rao TR, Shetty P, Rao SR. A rare case of formation of double ansa cervicalis. Neuroanatomy. 2007; 8: 26-27.

\section{AUTHOR(S):}

1. Dr. Shilpi Agarwal

2. Dr. Pooja Bhadoria

3. Dr. Neelam Vasudeva

\section{PARTICULARS OF CONTRIBUTORS:}

1. Senior Resident, Department of Anatomy, Maulana Azad Medical College, Bahadur Shah Zafar Marg, New Delhi, India.

2. Senior Resident, Department of Anatomy, Maulana Azad Medical College, Bahadur Shah Zafar Marg, New Delhi, India.

3. Director Professor and Head of Department, Department of Anatomy, Maulana Azad Medical College, Bahadur Shah Zafar Marg, New Delhi, India.
[10] Natsugoe $S$, Okumura $H$, Matsumoto $M$, Ishigami $S$, Owaki T, Nakano S. Reconstruction of recurrent laryngeal nerve with involvement by metastatic node in esophageal cancer. Ann Thorac Surg. 2005; 79(6):1886-89.

[11] Crumley RL, Izdebski K, McMicken B. Nerve transfer versus tefIon injection for vocal cord paralysis: a comparison. Laryngoscope. 1998; 98(11):1200-04.

[12] Laurentjoye M, Ricard AS, Caix P, Siberchicot F, Majoufre-Lefebvre $\mathrm{C}$. Tongue reconstruction with a bilateral infrahyoid flap innervated by Ansa Cervicalis after total glossectomy. Rev Stomatol Chir Maxillofac. 2011; 112:337-41.

[13] Vollala VR, Bhat SM, Nayak S, Raghunathan D, Samuel VP, Rodrigues $\mathrm{V}$, Mathew JG. A rare origin of upper root of ansa cervicalis from vagus nerve: a case report. Neuroanatomy. 2005; 4: 08-09.

[14] Sanes DH, Reh TA, Harris WA. Development of the nervous System $2^{\text {nd }}$ edition. New York: AP; 2000. p 189-97.

\section{NAME, ADDRESS, E-MAIL ID OF THE CORRESPONDING AUTHOR:}

Dr. Shilpi Agarwal,

C2 / 186, First Floor, Janakpuri, New Delhi-110058, India.

E-mail: drshilpiagg@gmail.com

\section{FINANCIAL OR OTHER COMPETING INTERESTS:}

None. 